\title{
Successful removal of impacted large bile duct stones using electrohydraulic lithotripsy with an ultraslim endoscope after Billroth II gastrectomy
}

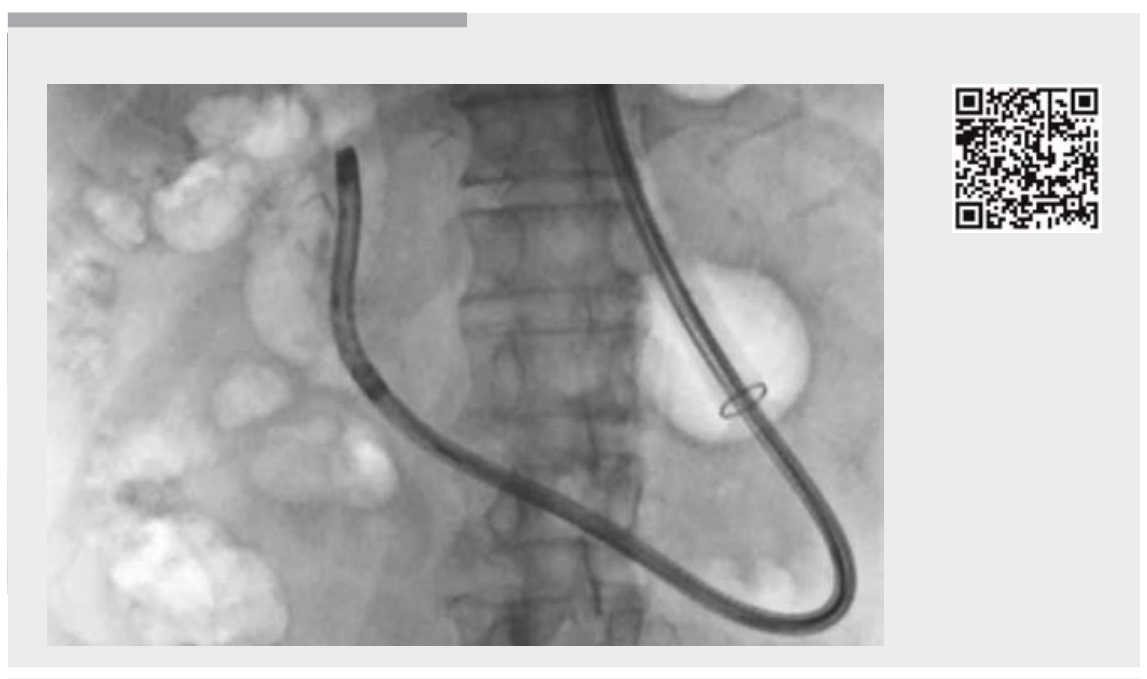

Video 1 Successful removal of impacted large bile duct stones using electrohydraulic lithotripsy using an ultraslim endoscope in a patient with Billroth II gastrectomy.

The diagnostic and therapeutic effectiveness of combined double-balloon endoscopy (DBE) using a short endoscope and peroral direct cholangioscopy with an ultraslim endoscope for altered gastrointestinal anatomy has been demonstrated [1 -5]. This method offers the following advantages over mother-baby cholangioscopy for bile duct stone treatment: single-operator use, wide working channel, favourable cost performance, and high image resolution. We treated impacted large bile duct stones using electrohydraulic lithotripsy (EHL) and an ultraslim endoscope in a patient who had undergone Billroth II gastrectomy.

A 75-year-old man was referred to our hospital for treatment of bile duct stones. He had undergone Billroth II gastrectomy for gastric cancer. Complete stone removal at the previous hospital was difficult, and a plastic stent had been placed. Abdominal computed tomography showed large stones stuck in the bile duct (largest stone diameter, $25 \mathrm{~mm}$ ) ( $\triangleright$ Fig. 1). We therefore planned to use EHL to crush the stones ( $\triangleright$ Video 1$)$.
First, we advanced a short DBE scope (EI580B; working length 1550 mm; Fujifilm, Tokyo, Japan) to the papilla and dilated the papilla using a $15-\mathrm{mm}$ balloon catheter. Then, we lifted the scope loop, and straightened it. The DBE scope was then exchanged for an ultraslim endoscope (EG-L580NW7; outer diameter $5.8 \mathrm{~mm}$; working channel $2.4 \mathrm{~mm}$; Fujifilm), leaving the overtube in place with balloon inflation $[1,2,5]$. The ultraslim endoscope was advanced to the papilla and inserted directly into the bile duct. We performed EHL for stone removal with manual water injection from the working channel and/ or using an endoscopic water pipe system ( Fig.2). After crushing the stone sufficiently, we completely removed the stone fragments using a 5-Fr basket (Memory Basket; Cook, Osaka, Japan) and saline injection and the ultraslim endoscope ( Fig.3, $>$ Fig.4, $>$ Fig.5). The procedure time was 30 minutes and there were no adverse events.

This combined method was useful for the removal of large stones using $\mathrm{EHL}$ and achieved clear vision during the endoscopic procedure.

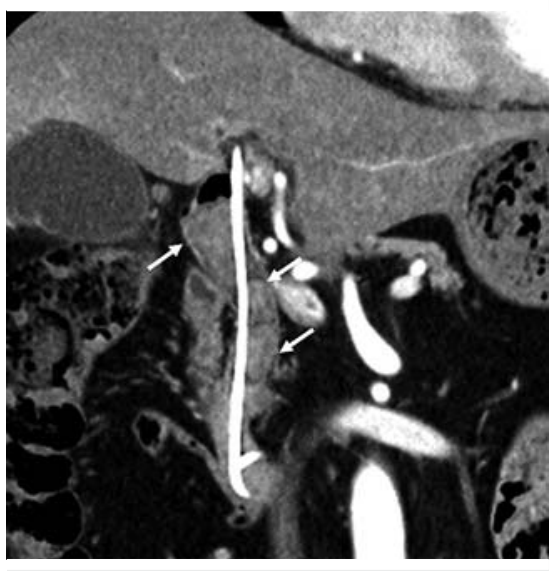

- Fig. 1 Computed tomography revealed numerous impacted stones in the bile duct (arrows); maximum size, $25 \mathrm{~mm}$ in diameter.

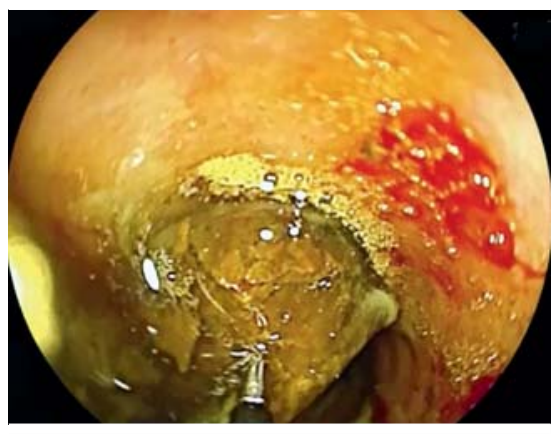

- Fig. 2 Endoscopic image during electrohydraulic lithotripsy.

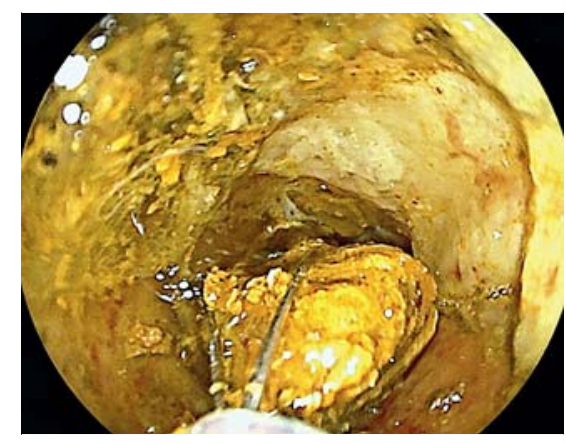

- Fig. 3 Stone removal using a 5-Fr basket and an ultraslim endoscope.

Endoscopy_UCTN_Code_TTT_1AR_2AH 


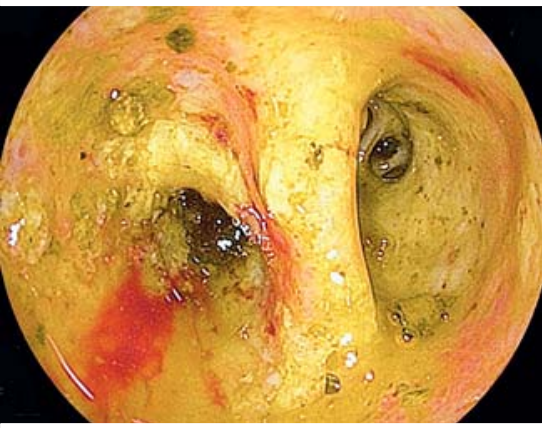

- Fig. 4 Endoscopic image after stone removal.

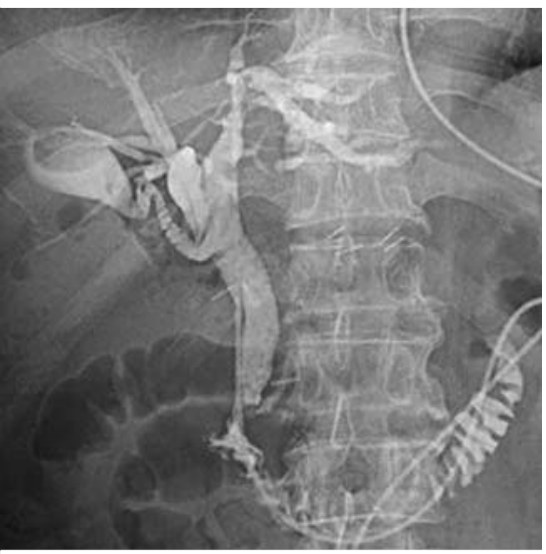

- Fig. 5 Cholangiogram from the endoscopic nasobiliary tube. The stones had been removed completely.

Competing interests

None
The authors

Kazuyuki Matsumoto, Hironari Kato, Shigeru Horiguchi, Daisuke Uchida, Takeshi Tomoda, Shinichiro Muro, Hiroyuki Okada

Department of Gastroenterology and Hepatology, Okayama University Graduate School of Medicine, Dentistry and Pharmaceutical Sciences, Okayama, Japan

\section{Corresponding author}

\section{Kazuyuki Matsumoto, MD}

Department of Gastroenterology and Hepatology, Okayama University Graduate School of Medicine, Dentistry and Pharmaceutical Sciences, 2-5-1 Shikata-cho, Okayama 700-8558, Japan

Fax: +81-86-2255991

matsumotokazuyuki0227@yahoo.co.jp

\section{References}

[1] Matsumoto K, Tsutsumi K, Kato $\mathrm{H}$ et al. Effectiveness of peroral direct cholangioscopy using an ultraslim endoscope for the treatment of hepatolithiasis in patients with hepaticojejunostomy (with video). Surg Endosc 2016; 30: 1249-1254

[2] Mönkemüller K, Toshniwal ], Zabielski M. Therapeutic endoscopic retrograde cholangiography and cholangioscopy (ERCC) combining a single-balloon enteroscope and an ultraslim endoscope in altered gastrointestinal anatomy. Endoscopy 2012; 44: E349E350
[3] Skinner M, Popa D, Neumann H et al. ERCP with the overtube-assisted enteroscopy technique: a systemic review. Endoscopy 2014; 46: 560-572

[4] Matsumoto K, Tsutsumi K, Baba Y et al. Successful biliary drainage with peroral direct cholangioscopy in a patient with Roux-en-Y hepaticojejunostomy for congenital biliary dilatation. Endoscopy 2015; 47: E497-E498

[5] Saragai Y, Uchida D, Kato $\mathrm{H}$ et al. Biliary cannulation technique with ultraslim endoscope for a patient with Billroth II gastrectomy. Endoscopy 2019; 51: E38 -E39

\section{Bibliography}

DOI https://doi.org/10.1055/a-0896-2498

Published online: 9.5.2019

Endoscopy 2019; 51: E265-E266

(c) Georg Thieme Verlag KG

Stuttgart · New York

ISSN 0013-726X

\section{ENDOSCOPY E-VIDEOS}

https:/|eref.thieme.de/e-videos

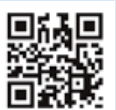

Endoscopy E-Videos is a free access online section, reporting on interesting cases and new techniques in gastroenterological endoscopy. All papers include a high quality video and all contributions are freely accessible online.

This section has its own submission website at https://mc.manuscriptcentral.com/e-videos 